\title{
P R E F A C E
}

T $\mathrm{TE}$ four centuries known in Japanese history as the Medi1 eval Era were dominated politically by the society of samurai, men of a noble breed who, ideally, lived and fought in accordance with an estimable code of chivalrous conduct and loyalty. Its genesis in the mid-twelfth century was amidst the violence of war; its demise in the late sixteenth century was amidst even greater turbulence and disorder. The relatively tranquil middle years are characterized by the arts which flowered within the serene, scholarly confines of Zen monasteries or amidst the elegant setting of the court of the Ashikaga Shogun in Kyoto. Flowerarrangement, the tea ceremony, monochrome painting, drylandscape gardening, the no drama-these are the arts from that era in history, and which even today epitomize traditional Japanese culture. The quiet, somber mood and subdued tone of beauty set the Medieval Era distinctly apart from the cultural periods between which it stands in time. The era was preceded by the classical Heian Period (794-1185), during the efflorescence of which a culture of remarkable sensual beauty was evolved by a small society of leisured aristocrats centered around the Imperial Court, and followed by the buoyant, colorful Edo Period (1600-1867), when artistic tastes and fashion were dictated by a new pleasure-seeking class of plebeian townsmen.

The ballad-drama known as kówaka is a legacy of the turbulent years of the Medieval Era. It was created and performed widely before a samurai audience during the middle and late sixteenth century. The stories are drawn mostly from the tumultuous early decades of the era; they treat dramatic highlights of the heroic struggle between the Genji and the Heike as well as other stirring martial adventures that make up the epic material in Japanese literature. The code of fidelity honored by samurai of later ages was, indeed. inspired in large measure by 
the gallantry and heroism described in such literature. Although the kōwaka was an art of major significance, favored especially by warring feudal barons and their samurai retainers, it was quickly forgotten once the warrior was transformed into the sedentary sword-bedecked aristocrat of the Edo Period. Long considered an extinct art, its existence was rediscovered only in the present century.

We would know very little about the kôwaka had it not been perpetuated in geographical isolation, relatively uninfluenced by the mainstream of social and artistic evolution. It exists today only in a hamlet called ōe, situated deep in the provincial recesses of Kyushu. Learned acquaintances in Japan have often commented to me on the remarkable similarity between the kowwaka and some folk art they had once observed. I have analyzed the three which have been mentioned most prominently in this respect-the daimokutate and Yamato manzai of Nara and the ennen no mai of the Motsuji monastery in Hiraizumi-and have found that they are artistically of a different order from the kôwaka; and that the fragmentary similarities that do exist attest only to their being products of one culture. This status of uniqueness of the kowaka can be challenged, of course, with the uncovering of new material. The opportunity to study the kōwaka as a performing art-a composite art comprising elements that are visual, aural, and verbal-has, nevertheless, given me the opportunity to penetrate the vagueness which has shrouded the circumstances of its flourish and decline in history.

The present study is organized in two parts. Part One is a treatment of the kowwaka as a performing art. I have described the history of the kôwaka in considerable detail, tracing and delineating all artistic elements that may have contributed to its formation. A complete and technical treatment was necessary, I felt, if the discussion were to be in any way conclusive; for explanations of origins inevitably falter with the new appearance of yet another suspected antecedent. Although I have touched upon every possible source of influence, however remote, there may be others unknown to me. In preparing the chapter on the history of the kōwaka, I have relied heavily on past studies by Japanese scholars, especially those of the late Takano Tatsu- 
yuki. Their conclusions and hypotheses have in many instances served as points of departure for further inquiry; and if $I$ have pointed out inconsistencies in their findings, I have been able to do so owing largely to my advantage of having collated their research results. The writing of the third chapter ("The Köwaka Today") was, of course, based on my own observations and information provided largely by the residents of Ōe Village.

Part Two, which may be read independently, is a study of the kowaka libretto; it consists of an analysis and description of the texts and two complete translations. The full textual annotation is the first to appear in any language. The kowwaka text is sixteenth-century Japanese literature, and its stylistic divergence from contemporary Japanese approximates that between the styles of King James and present-day English. I have tried to reproduce the tone and style of the original-as it may appear to the Japanese today, at least-not by resorting to archaisms but by rendering faithfully the literary conventions which characterize the kowwaka. I have not attempted to make the texts appear more charming in translation than they are in the original. Lyrical passages may occasionally, but fortuitously, be cast in meters which are discernibly English; it is hoped that in such instances the effect will not be disagreeable. Epithets, titles, and names have been rendered in translation if their imagistic qualities predominate over their value as utterances: thus, "Inner Wilds" for Uchino and "Hall of the Valley" for Tani-no-do. Others I have transcribed: for example, nyūdō ("one who has entered the [Buddhist] Way"), which on the Japanese ear seems to register primarily as a sound symbolism rather than a dimorphemic term of description. Colorful words in the Japanese have not been allowed to pale in translation: so we have "bow hand" and "steed hand" for yunde and mete rather than "left hand" and "right hand," their meanings by implication. I have enclosed in square brackets [] only words which are neither stated explicitly nor clearly understood in the Japanese text. I have not aimed at achieving consistency in such matters of style with but one exception: all personal names of Japanese and Chinese are cited, as is customary, with the surname first.

I had hoped, when I began this study, to synthesize the aesthetic effect of the performance of this ballad-drama, but I find in the 
end that what I can offer amounts to little more than fragmentary descriptions of its component elements. My original intention may itself have been pretentious, though I suspect that such a total description of aesthetic meaning is what scholars of the performing arts aspire to achieve.

The esteemed Sasano Ken in 1943 compiled a valuable compendium of source material relating to the kowaka-the Köwakabukyoku shu, which I have used liberally-with the expressed hope that it may enable someone to write a definitive literary and historical study of the kowaka. The present study has its obvious limitations. An acquaintance in depth with the many lesser topics discussed would have been desirable. Parts of the discussion of traditional forms of Japanese music are only as reliable as the technical studies which I have consulted. My treatment of the choreography and music of the kowwaka may more properly be termed descriptions rather than analyses. It lies beyond the scope of the present study, for instance, to treat the problem of defining the musical modes employed in köwaka melodies, for this is something that will require a major effort by a competent musicologist. It is my hope that the present study will be of value to yet another inquirer who may be able to illuminate such relevant areas. Other shortcomings will have been due to my inability to consult a number of unpublished sources.

$$
\text { J. T. A. }
$$

Los Angeles, California

March, 1963 